\title{
Faster connections for 1996
}

\section{Washington}

THE apparent lack of urgency with which the United States is taking commercial advantage of supercomputers and highspeed telecommunications, two areas where the country has an undoubted technological lead, was the focus of two congressional hearings last week.

The House of Representatives committee on Science, Space and Technology bemoaned the failure of US industry to purchase supercomputers as eagerly as their Japanese competitors, even though one American company, Cray, holds three-quarters of the world market. And at a hearing of the Senate committee on Commerce, Science and Transportation, witnesses and senators were almost unanimously enthusiastic in their endorsement of a proposal to build a nationwide high-speed computer network by 1996 .

The recent withdrawal of Control Data Corporation from the supercomputer manufacturing business has prompted doubts about the prospects for Cray's success against emerging Japanese competitors such as NEC, Hitachi and Fujitsu. Although the worldwide supercomputer market, at about $\$ 1,000$ million, is not by itself a large part of the US economy, it was portrayed in both hearings as essential to research and development in technological industry as a whole. John five years to build a 3-gigabit-a-second computer network connecting universities, government laboratories, industry and even schools.

The aim is to encourage widespread innovation and use of computer and communications technology by making it available to all. The eventual goal is for the network to be run as a commercial enterprise, but the introduction of the bill amounts to a recognition that market forces alone do not provide enough pressure for business interests to undertake the long-term investment needed.

The National Science Foundation (NSF) already operates, through an industrial consortium called MERIT, a national computer network operating at 1.5 megabits a second. Since its inauguration last year (Nature 334, 374; 1988), traffic on NSFNET has increased by about 30 per cent a month, and an enhancement to 45 Mbits per second will be needed next year if the network is not to be overloaded.

The apparently insatiable demand for transmission capacity gives Gore hope that the proposed 3-Gbit network will have crossed the threshold to feasible commercialization almost as soon as it is built. In Gore's bill, the necessary research and development will be handled by the Defense Advanced Research Projects Agency (DARPA), but the coordination

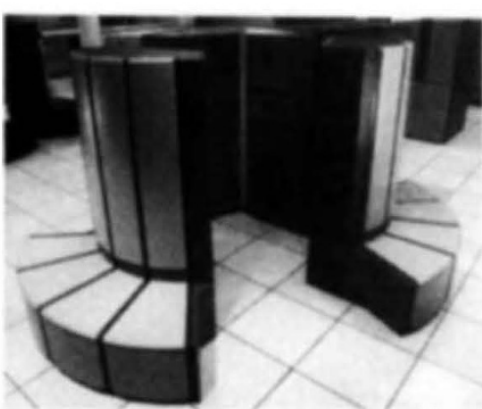

Market leader and a pretender. The Cray Y-MP8 (above), and NEC's new SX-3 (right).

Rollwagen, chairman of Cray Research, observed that his company had sold supercomputers to 16 car manufacturers, of which only three were US companies.

Asked why it mattered whether industries bought US or Japanese supercomputers, as long as they used them, Rollwagen argued that his company thrived and developed new products by listening to the needs of its customers: if his company failed, it would be because industry generally failed to understand what supercomputers could do.

With signs of another US technological lead slipping away, Senator Albert Gore (Democrat-Tennessee) introduced earlier this year the National High-Performance Computer Technology Act, one section of which would set aside $\$ 1,750$ million over

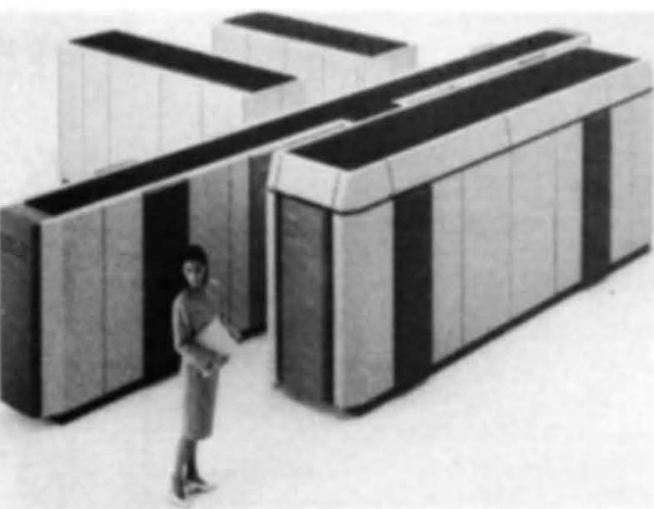

and management of the project will be overseen by the NSF. The Department of Commerce, the National Security Agency and the National Institutes of Science and Technology are also involved.

The traditional way of financing such a plan would be to estimate how much each agency needs and put the contributions into the federal budget at the appropriate places, but this would not guarantee that all parts of the programme would get the money they need. To get around this, the bill gives all of the money to the Office of Science and Technology Policy (OSTP), which would in turn allocate it as needed to the various agencies. Because the bill gives administrative powers over other agencies to a body which has so far acted only in an advisory capacity, this unprece-

\section{Europeans to design chips for everything? Vienna}

EUROPEAN microelectronics collaboration on an unprecedented scale was agreed last week by five nations and the European Community (EC) Commission as well as three electronics companies. The JESSI (Joint European Submicron Silicon) project will invest as much as 3,800 million ECU (some $\$ 4,000$ million) over eight years on the eventual development of a 64-megabit silicon memory chip. But around one-third of the proposed budget will be devoted to designing chips for special applications, and nearly one-quarter will go to research on design and integration methods.

JESSI was announced by the West German government, one of its sponsors, in February (see Nature 337, 682; 1989). France, Great Britain, Italy and the Netherlands are also participating, as are electronics companies Siemens, Philips and SGS-Thomson. British involvement in JESSI will focus primarily on the development of application-specific integrated circuits or ASICs. These so-called "designer chips" represent a large share of the market.

Provisional approval of JESSI under the 19-country Eureka programme, pending settlement of a few minor details, was announced in Vienna last week at a meeting of industry ministers. By being brought under the Eureka umbrella, JESSI can be harmonized with related European initiatives, which might have made the EC Commission more comfortable about putting money into it. The EC contribution is expected to be 25 per cent of the $\mathbf{5 5 0}$ million ECU start-up costs. A decision will be made later about EC participation beyond an initial 18-month period. Half of the funding will be provided by the companies involved, and the remaining 25 per cent will come from individual national governments.

The rousing start for JESSI reflects European fears of being shut out of the market for chips by the Japanese, who produce a large percentage of the chips available on the world market. Whether JESSI will be open to participation by US companies like IBM remains an open question; JESSI leaders have made this dependent on US companies allowing European participation in Sematech, a US microelectronics initiative.

Steven Dickman

dented method of funding will undoubtedly run into trouble.

Supercomputers and networks are seen as a touchstone of US technological prowess, and Gore's bill has wide bipartisan support. The hope is that Congress will give serious consideration to an innovative method of financing the network; such an innovation could be as important to the United States as the substance of the bill itself.

David Lindley 